\title{
Opleiding van elektriese en elektroniese ingenieurs met groter klem op inligtingstegnologie
}

\author{
J. Gouws \\ Departement Elektriese en Elektroniese Ingenicurswese, Randse Afrikaanse Universiteit, \\ Posbus 524, Aucklandpark, 2006 \\ jg@ingl.rau.ac.za
}

Onvang 29 Julie 1999; aanvaar 3 Februarie 2000

\section{UITTREKSEL}

Hierdie artikel fokus op die vraag of meer komponente van inligtingstegnologie by leerplanne vir opleiding van elektriese en elektroniese ingenieurs ingestuit behoort te word, of nie. Buitelandse tendense word korliks ontleed aan die hand van 61 atvertensies van vakatures by akademiese instellings en in die Amerikanse statasdiens en indastrie. Hierdie advertensies weerspieël 'n sterk behoefte aan ingenieurs met formele opleiding in inligtingstegnologie, en toon aan dat 'n groot aantal buitelandse universiteite sulke opleiding verskaf. In Suid-Afrika is daar tans nog wyd tuiteenlopende standpunte hieroor. Die outeur glo dat die tendens van 'n krimpende gaping tussen inligtingstegnologie en elektriese en elektroniese ingenieurswese wêreldwyd sal voortduur - wat dit noodsataklik maak dat elektriese en elektroniese ingenieurstudente 'n keuse behoort te kry tussen tradisionele opleiding en opleiding met groter klem op' inligtingstegnologie.

\begin{abstract}
Anstract
Training of electrical and electronic engineers with greater emphasis on information technology

This paper focuses on the question whether; or not, nore components of information technology should be included in the curricula for training of electrical and electronic engineers. Foreign trends are briefly analysed, based on 61 advertisements of vacancies at academic institutions and in the American government and industry. These advertisements reflect a strong demand for engineers with formal training in information technology, and show that a large number of foreign universities offer such training. In South Africa, there are wide-ranging viewpoints on this issue. The author believes that the trend of a narrowing gap between information technology and electrical and electronic engineering will continue internationally-making it essential that electrical and electronic engineering students should have a choice between traditional training and training wilh more emphasis on information technology.
\end{abstract}

\section{INLEIDING}

Dit word toenemend mociliker om fasette van die lewe te identifiseer wat nie direk of indirek geraak word deur snelle ontwikkelings op die gebied van inligtingstegnologie (IT) nie. Hierdie term omsluit velde soos rekenartegnologie, rekenaaringenieurswese en programmatuuringenieurswese. Die ontwikkeling van inligtingstegnologie word hoofsaaklik gedoen deur elektriese en elektroniese ingenieurs, en deur rekenaarwetenskaplikes. Hierdie arlikel fokus op die vraag of inligtingstegnologic 'n groler plek behoort te kry in leerplanne vir elektriese en elektroniese ingenieurswese, of nie. Die vratag is nie of bestaande leerplanne in elektriese en elektroniese ingenieurswese algeskaf moet word of nie, maar eerder of 'n alternatiewe leerplan, met 'n groter komponent inligtingstegnologie daarin vervat, as keuse vir studente gegee behoort te word. Ten einde hierdie vraag te beantwoord, word daar eerstens 'n ontleding gedoen van 61 buitelandse akademiese, staats- en industrievakatures; tweedens word enkele Suid-Afrikaanse tendense ondersock; en laastens spreek die outeur 'n mening uit oor die pad vorentoe.

\section{BUITELANDSE TENDENSE}

Die IEEE (Institute ol Electrical and Electronics Enginecrs, Inc.) is een van die grootste ingenicursverenigings ter wêreld, en adverteer maandeliks vakatures in IEEE Spectrum - primêr gerig op elektriese en elektroniese ingenieurs. Alhoewel die geadverteerde vakatures hoofsaaklik (maar nie uitsluitlik nie) in die Verenigde State van Amerika is, kan die advertensies as 'n algemene aanduiding gebruik word van internasionale tendense in elekıriese en elektroniese ingenieurswese. Tabel 1 toon voorbeclde van die akademiese poste wat in dic Maart 1999-uitgawe van IEEE Spectrum' geadverteer is; en tabel 2 toon voorbeelde van die staats- en industrieposte wat in diesellide uitgawe geadverteer is. (Alhoewel dit ' $n$ beperkte steekproef is, het die outeur vir etlike maande lank 'n soortgelyke analise gedoen, en daardeur bevestig dat dit wat hier aangebied worl. 'n algemene tendens weerspieël.)

'n Ontleding van die 38 geadverteerde akademiese poste en van die 23 staats- en industrieposte toon:

- Sestien advertensies is geplaas deur 'n akademiese departement of afdeling met elektries / elektronies gckombineer met rekencar / inligting in dic naam daarvan.

- Nege advertensies is geplaas deur 'n akademiese departement of afdeling met 'n tradisioncle naam soos Departement Elektriese en Elektroniese Ingenieurswese. (Hier is net agt departemente ter sprake, aangesien twee van dic advertensies in hierdic kategoric deur dieselfde departement geplaas is.)

- Dertien advertensies is geplaas deur akademiese departemente soos rekenaarwetenskap, fisika, of biomediese ingenieurswese; deur navorsingsentrums; of deur ingenieursfakulteite in die algemeen (bv. dekaansposte).

- Sestien van die 25 akademiese departemente wat 'n vakature 
Tabel 1 Voorbeelde van akademiese poste geadverteer in die Maart 1999-uitgawe van IEEE Spectrum '

\begin{tabular}{|c|c|c|}
\hline Instansie & Naam van departement / aldeling & Aanhaling uit advertensie \\
\hline $\begin{array}{l}\text { Arizona State } \\
\text { University }\end{array}$ & Telecommunications Research Center & $\begin{array}{l}\text { "camed doctorate degree in Electrical Enginecring. } \\
\text { Compuler Engineering, or a closely related field." }\end{array}$ \\
\hline $\begin{array}{l}\text { Arizona Siate } \\
\text { University East }\end{array}$ & $\begin{array}{l}\text { Electronics \& Computer Enginecring } \\
\text { Technology Deparment }\end{array}$ & $\begin{array}{l}\text { "lo teach computer sotiware and hardware courses and to } \\
\text { do research in the ... computer Technology program." }\end{array}$ \\
\hline $\begin{array}{l}\text { Bar-Ilan University } \\
\text { (Israel) }\end{array}$ & $\begin{array}{l}\text { Department of Electrical \& Computer } \\
\text { Engineering }\end{array}$ & $\begin{array}{l}\text { "Outstanding candidates in all areas of electrical } \\
\text { and computer engineering ...." }\end{array}$ \\
\hline $\begin{array}{l}\text { California Institute of } \\
\text { Technology }\end{array}$ & Computer Science Department & $\begin{array}{l}\text { "with possible joint appointment in Filectricill } \\
\text { Enginecring ..." }\end{array}$ \\
\hline $\begin{array}{l}\text { Chinese University of } \\
\text { Hong Kong }\end{array}$ & Department of Information Engineering & "PhD ... in any relevant areas in Information Enginecring." \\
\hline Drexel University & $\begin{array}{l}\text { Electrical \& Computer Enginecring } \\
\text { Department }\end{array}$ & $\begin{array}{l}\text { "We have particular interest in experts in ... and } \\
\text { Computer Engineering." }\end{array}$ \\
\hline $\begin{array}{l}\text { Georgia Institute of } \\
\text { Technology }\end{array}$ & $\begin{array}{l}\text { School of Electrical \& Computer } \\
\text { Enginecring }\end{array}$ & "Cindidates are sought in ... computer engineering; ...." \\
\hline $\begin{array}{l}\text { I-Shou University } \\
\text { (Taiwan) }\end{array}$ & $\begin{array}{l}\text { College of Electrical \& Information } \\
\text { Engincering }\end{array}$ & $\begin{array}{l}\text { "Electrical and Electronic Engineering. Information } \\
\text { Engineering, ..." }\end{array}$ \\
\hline $\begin{array}{l}\text { Illinois lnstitute of } \\
\text { Technology }\end{array}$ & $\begin{array}{l}\text { Department of Electrical \& Computer } \\
\text { Engineering }\end{array}$ & $\begin{array}{l}\text { "inviles applications ... in the areas of Computer } \\
\text { Engineering ...." }\end{array}$ \\
\hline $\begin{array}{l}\text { McMaster University } \\
\text { (Camada) }\end{array}$ & $\begin{array}{l}\text { Department of Electrical \& Computer } \\
\text { Engineering }\end{array}$ & $\begin{array}{l}\text { "has identified Information Technology" as an } \\
\text { area of strategic priority..." }\end{array}$ \\
\hline $\begin{array}{l}\text { National Chiao Tung } \\
\text { University (Taiwan) }\end{array}$ & $\begin{array}{l}\text { Department of Electrical and Control } \\
\text { Engineering }\end{array}$ & $\begin{array}{l}\text { "eamed doctorate in either Electrical Engineering. } \\
\text { Computer Engineering. or a related specialty." }\end{array}$ \\
\hline $\begin{array}{l}\text { New Mexico Institute of } \\
\text { Mining and Technology }\end{array}$ & Electrical Enginecring Faculty & $\begin{array}{l}\text { Preferenee will be given to candidates who will } \\
\text { "strengthen the department in ... computer engineering." }\end{array}$ \\
\hline $\begin{array}{l}\text { New Mexico State } \\
\text { Universily }\end{array}$ & $\begin{array}{l}\text { School of Electrical \& Compuler } \\
\text { Engineering }\end{array}$ & $\begin{array}{l}\text { "Applicants from all areas of EE [Electrical Enginecring | } \\
\text { or ECE |Electrical and Computer Engineering | ..." }\end{array}$ \\
\hline University of Floridal & $\begin{array}{l}\text { Department of Electricial \& Computer } \\
\text { Engineering }\end{array}$ & $\begin{array}{l}\text { "in the areas of communications or computer } \\
\text { enginecring, ..." }\end{array}$ \\
\hline University of Kansas & $\begin{array}{l}\text { Department of Electrical Engineering } \\
\text { and Computer Science }\end{array}$ & $\begin{array}{l}\text { "earned doclonate in computer science. computer engineering. } \\
\text { or closely related computing field is reguired." }\end{array}$ \\
\hline $\begin{array}{l}\text { University of } \\
\text { Washinglon }\end{array}$ & Image Computing Systems Laboratory & $\begin{array}{l}\text { "Five years" experience is needed in ... computer } \\
\text { architecture ..." }\end{array}$ \\
\hline Utah State University & $\begin{array}{l}\text { Department of Electrical \& Computer } \\
\text { Engineering }\end{array}$ & $\begin{array}{l}\text { "seeks al Department Head } \mid \ldots \text { will } \mid \text { an earned doctorale in } \\
\text { electrical engineering, compuler engineering, or a related } \\
\text { area ...." }\end{array}$ \\
\hline $\begin{array}{l}\text { Virginia Military } \\
\text { Instilute }\end{array}$ & Military College & "areas normally considered part of Computer Engineering." \\
\hline $\begin{array}{l}\text { Washington State } \\
\text { University, Spokane }\end{array}$ & $\begin{array}{l}\text { School of Electrical Engineering and } \\
\text { Computer Science }\end{array}$ & "full-time ... position in compuler engineering." \\
\hline $\begin{array}{l}\text { Worcester Polylechnic } \\
\text { Institute }\end{array}$ & $\begin{array}{l}\text { Electrical \& Computer Engineering } \\
\text { Department }\end{array}$ & "computer engineering ...." \\
\hline
\end{tabular}

spesifick in efektriese en elektroniese ingenieurswese advertecr, het die tradisioncle nalam Departemem Elektriese en Elektroniese Ingenieurswese vervang met name soos Departement Elektriese en Rekenaringenienrswese of Departement Elektriese en Inligtingsingenieurswese. Hicruit word algelei dat inligtingstegnologic so 'n belangrike rol specl in die werksaamhede van hierdic departemente, dat die terme rekenatr of inligting in die name daarvan ingesluit word.

- Twintig van die 38 geadvertecrde akademiese poste vereis pertinente kundighede in inliglingstegnologie; terwyl 18 valn die 23 geadverteerde staats- en industrieposte sulke kundighede vereis. Dic vereisles is baie spesifick, en vra dikwels vir 'n formele kwalilikasie in rekenaar- en/of programmatuuringenieurswese. Hieruit kan eerstens afgelei word dat daar 'n groot bchoefte in die arbeidsmark bestian vir persone met formele opleiding in intiglingstegnologie; en tweedens dat datar butelandse universitcite is wall sulke opleiding verskal:

\section{STANIPUNTE EN TENDENSE IN SUID- AFRIKA}

In Suid-Alrika is daar uiteenlopende st:andpunte vir en leen aanpassing van lecrplanne vir elcktriese en cleklronicse ingenieurswese ten einde 'n groter komponent inliglingstegnologie in te sluit. Enkele voorbedde hiervan word in lahel 3 getoon.

In die lig valn bogenoemde uileenlopende standpunte is die insluiting van 'n groter komponent inliglingstegnologic in leerplanne vir elektriese en elektroniese ingenieurswese nog nic 'n algemene verskynsel in Suid-Alrika nic. Die Randse Afrikaanse Universitcit (RAU) en dic Universiteit van Pretoria 
Tabel 2 Voorbeelde van staats- en industrievakatures in die Maart 1999-uitgawe van IEEE Spectrum ${ }^{1}$

\begin{tabular}{|c|c|c|}
\hline Organisasie & Pos & Aanhaling uit advertensic \\
\hline $\begin{array}{l}\text { Colorado Department of Labor } \\
\text { and Employment }\end{array}$ & Programmers / Analysts & $\begin{array}{l}\text { "Plan. develop, test, implement \& } \\
\text { maintain computer programs." }\end{array}$ \\
\hline $\begin{array}{l}\text { Colorado Department of Labor } \\
\text { and Employment }\end{array}$ & Programmers / Analysts & $\begin{array}{l}\text { "Must have experience as Programmer / } \\
\text { Analyst or Senior Software Engineer." }\end{array}$ \\
\hline HNC Soltware (San Diego) & Staff Scientist & $\begin{array}{l}\text { "Requires an MS or PhD in Computer Science. } \\
\text { Electrical Engineering. ..." }\end{array}$ \\
\hline $\begin{array}{l}\text { Illinois Department of } \\
\text { Employment Security }\end{array}$ & Senior Soliware Engineer & $\begin{array}{l}\text { "design, development and maintenance of } \\
\text { object-oriented GUl sotiwate...." }\end{array}$ \\
\hline $\begin{array}{l}\text { Illinois Department of } \\
\text { Employment Security }\end{array}$ & Design Engineer & $\begin{array}{l}\text { "microprocessors to perlorm system architecture. } \\
\text {..." }\end{array}$ \\
\hline $\begin{array}{l}\text { Indiana Department ol Workloree } \\
\text { Development }\end{array}$ & Control Engineer & $\begin{array}{l}\text { "using knowledge of electrical engineering, } \\
\text { computer software, ..." }\end{array}$ \\
\hline $\begin{array}{l}\text { Indiana Department of Workforce } \\
\text { Development }\end{array}$ & Validation Engineer & "MS in Computer Enginecring ...." \\
\hline $\begin{array}{l}\text { Indiana Department of Workforec } \\
\text { Development }\end{array}$ & $\begin{array}{l}\text { Senior Manufacturing Development } \\
\text { Enginecr }\end{array}$ & $\begin{array}{l}\text { "Experience must ... include development \& } \\
\text { validation of software test systems." }\end{array}$ \\
\hline $\begin{array}{l}\text { Indiana Department of Workforce } \\
\text { Development }\end{array}$ & Project Engineer & $\begin{array}{l}\text { "automatic and computer-integrated } \\
\text { manufacturing projects ... customized and } \\
\text { measurement soliware ..." }\end{array}$ \\
\hline Ken Brown \& Co. & Electrical Control Systems Engineer & $\begin{array}{l}\text { "Programming PLCs. PC based operator interface } \\
\text { software, configuration and installation." } \\
\end{array}$ \\
\hline $\begin{array}{l}\text { Multinational Automotive } \\
\text { Industry Manufacturer }\end{array}$ & Senior Development Engineer & $\begin{array}{l}\text { "will work in the algorithm / ultrassound sensor } \\
\text { team ..." }\end{array}$ \\
\hline $\begin{array}{l}\text { Multinational Automotive } \\
\text { Industry Manufacturer }\end{array}$ & $\begin{array}{l}\text { Advanced Electronic Packaging } \\
\text { Design \& Reliability Rescarch } \\
\text { Engineer }\end{array}$ & $\begin{array}{l}\text { "Requires a Master of Science in Computer } \\
\text { System Enginecring ...." }\end{array}$ \\
\hline $\begin{array}{l}\text { National Institute of Neurological } \\
\text { Disorders and Stroke }\end{array}$ & Biomedical Engineer & $\begin{array}{l}\text { "preferably with emphasis on image processing/ } \\
\text { analysis, pattern recognition and computer vision." }\end{array}$ \\
\hline $\begin{array}{l}\text { Ohio Bureau of Employment } \\
\text { Services }\end{array}$ & Maintenance Technician & "PLC, ... robotic programming ...." \\
\hline $\begin{array}{l}\text { Tacoma Employment } \\
\text { Security Department }\end{array}$ & Project Manager & $\begin{array}{l}\text { "Plan, direct, coordinate activities of designated } \\
\text { computer systems projects ...." }\end{array}$ \\
\hline $\begin{array}{l}\text { Tacoma Employment } \\
\text { Security Department }\end{array}$ & Programmer / Analyst & $\begin{array}{l}\text { "From requirements develop specificaltions, } \\
\text { provide analysis, design, development ... of } \\
\text { required software ...." }\end{array}$ \\
\hline Texas Workforce Commission & Integrated Circuit Design Engineer & $\begin{array}{l}\text { "Requires a Masler's Degree in Compuler } \\
\text { Science..." }\end{array}$ \\
\hline Texas Workforce Commission & Electrical Engineer, Utilities & " programming and maintenance of PLC's ...." \\
\hline
\end{tabular}

Tabel 3 Voorbeelde van verskillende standpunte oor insluiting van meer inligtingstegnologie in leerplanne vir elektriese en elektroniese ingenieurswese

\section{STANDPUNTE TEN GUNSTE VAN STATUS QUO}

Die bestaande Icerplanne vir elektriese en elektroniese ingenieurswese werk vir baic jare lank recds goed, en moct ongesteurd gelaat word.

Die halfleefiyd van inligtingstegnologie is te kort om dit sinvol in ' $n$ universiteitslecrplan in te sluit.

Inligtingstegnologie behoort slegs as gespesialisecrde nagraadse kursus aangebied te word.

Suid-Afrika is 'n ontwikkelende land, waar daar gelokus moet word op basiese tegnologic.

Die nodige inligtingstegnologicvaardighede kan deur indiensopleiding verkry word.

\section{STANDPUNTE TEN GUNSTE VAN VERANIOERING}

Dit is noodsaaklik dat studente die keuse kry om 'n lectplan te volg wat gereeld hersien word, wat nuwe ontwikkelings insluit. en wat markbehoeftes bevredig.

Daar kan nie teruggedeins word van die behoelte aan opleiding in inligtingstegnologie, bloot omdat dit 'n vinnig veranderende veld is nic.

Nie alle ingenicursgraduandi stel belang in, of is geskik vir nagraadse studic nic.

Gevorderde tegnologie, soos IT, is ' $n$ noodsalaklike bousteen vir ckonomiese ontwikkeling.

Indiensopleiding is ' $n$ vorm van voortgesette opleiding, en nic geskik om basiese wetenskaplike heginsels mee te vestig nie. 
(UP) het egter in 1999 begin met nuwe inligtingstegnologiegerigte ingenicursleerplanne, wat bykomend tot die bestainde graadkursusse in elektriese en elektroniese ingenieurswese aangebied word. Gedurende Januaric 2000 was die getal RAU cerstejaarstudente wat vir hierdie nuwe leerplan geregistreer het, dieselfde as vir die RAU Ingenieurslakulteit se ander drie leerplanne (Elcktries en Elektronies, Meganies en Vervaardiging, en Sivicl en Stedelik) gesamentlik. Dic huidige aanduidings is dus dat hierdic nuwe opsie deur studente verwelkom en aangegryp word. Verder het verskeie werkgewers ook reeds baie positicl gereageer op die moontlikhede wat deur hicrdic nuwe leerplanne gebied word.

Die nuwe RAU-lecrplan word gesamentlik aangebied deur die Departement Elektriese en Elektroniese Ingenieurswese en die Departement Rekcnaarwetenskap. Sulke samewcrking is noodsalaklik wannecr beperkte hulpbronne - veral in 'n ontwikkelende land soos Suid-Afrika - optimaal aangewend moct word. Uit dic ontleding in aldeling 2 hicrbo, blyk dit dat sulke samewerking nic ooglopend voorkom by buitelandse universiteite nic. Dic advertensic van dic Rekenaarwetenskap Departement aan die California Institute of Technology, is die enigste cen wat dic moontlikheid van 'n gesamentlike aanstelling tussen hulself en die Departement Elektriese Ingenieurswese aldaar, pertinent nocm.

\section{DIE PAD VORENTOE}

Die buitelandse tendense wat in afdeling 2 hicrbo genoem word, en dic entoesiasme wat by RAU crvaar word vir die insluiting van 'n groter komponent inligtingstegnologic in 'n lecrplan vir elektriese en elektroniese ingenicurswese, dui aan dat hierdic konsep in die tockoms 'n meer algemene verskynsel sal word. Om egter bloot inligtingstegnologic in dic naam van 'n nuwe leerplan in te sluit, sonder om veel aan die inhoud te verander, of om eenmalig 'n nuwe lecrplan uit te werk, en dan te dink dit is goed genoeg vir baic jare vorentoc, sal ongelukkig nie werk nic. Ontwikkelinge in die veld van inligtingstegnologie vind hiervoor te vinnig plaas, en lecrplanne sal gerceld hersien móćt word.

$\mathrm{Mct}$ opleiding in inligtingstegnologic kan dic klem nie nel lê op inligting nic, maar dit moct op alle aspekte van inligtingstegnologie val. Tans lyk dit dikwels asol dic versameling $\mathrm{cn}$ stoor van inligting die oorhecrsende doclwit is wanneer inligtingstegnologie ter sprake is - sonder dat daar krities gekyk word na die betroubaarheid en die waarde van die inligting, of na die gepaardgaande apparatuur- en programmatuur-bchocftes. Dalar is vele ondernemings wat 'n bestuursinligtingstelsel ten duurste laat implementeer hel, en dan kla dat die opbrengs op die belegging negaticl is. Dic redes hicrvoor is meestal:

- Daar word 'n groot infrastruktuur opgebou om inligting te versamel en te stoor. Te min aandag word egter gegee aan behoorlike ontwerp (behoeftestelling, konsepontwerp, keusevernouing en detailontwerp) van die inligtingstelsel, locts en evaluasie lydens implementering, evaluering van ellektiwiteit van alle aspekte van die implementering, sinvolie interpretasic van die inligting, gebruik van die inligting om die onderskeic besigheidsareas van dic onderneming te optimeer, en moontlike gedeclde gebruike van die apparaluur en programmatuur.

- Die implementering van dic inligtingstelsel is in baic gevalle nic optimaal nic, omdat dit geïmplementeer word deur persone wat slegs 'n implementeringsresep alangeleer het, en wat dit dan slaafs navolg by die een kliënt na die ander. Dié persone begryp dikwels nic dic onderliggende besigheidsbeginsels van dic onderneming, van die prosesse, en van die totale inligtingstegnologie-pakket nie. Weens oordrewe klem op dic implementering van bestuurs- inligtingstelsels en op die aanvanklike versameling en stoor van inligting, word tekortkominge dikwels eers te laat besel en verstaan.

- Die besigheidsprosesse walr die stelsel geimplementeer word, word dikwels geformulecr om by dic beskikbare inligtingstegnologic-hulpmiddels aan te pas, in plats van andersom.

Om hierdic probleme te oorkom, is dit noodsalaklik dat behoorlik opgeleide ingenicurs betrokke sal wees by dic ontwerp. implementering, gebruik en opgradering van inligtingstelscls. 'n Denkwyse-verskuiwing, vanaf die inligtingsera na die e'a van kennis, is hiervoor noodsaaklik. Dit is egter nie genoeg om bloot ingenieurs te hê wat ook maar net rekenalarpakkette blindelings kan gebruik nic. Nic-ingenicurs kan dit ook doen. Daar is ingenieurs nodig wat dic onderliggende beginsels begryp van die stelsel / proses wat besiuur word en waarvan inligling versamel word, wal hicrdie beginsels in verband kan bring met die oplimale aanwending van die stelsel/ proses, wat weet watter inligting versamel moet word en watter nic, wat weet hoe om 'n optimale kombinasie van apparatuur en programmatuur saam te stel, wat weet hoe, om die integriteit van die inligting le verseker. en wal weet wat on uiteindelik met die inligting te doen.

Om sulke ingenicurs te kry, is dit noodsaaklik dat die opsie bestaan om 'n kursus in elektriese en elcktroniese ingenieurswese te volg, met 'n beduidende komponent inligtingstegnologickursusse in die lecrplan ingesluit. Ingenicursfakulteite sal egter moet scker maak dat daar nie bloot ingenicurs opgelei word wat valardig is met "rekenaarresepte", sonder om die grondliggende ingenicursbeginsels te verstaan nie. Die gevare van blindelingse vertrouc op rekenaars moet tydens opleiding hy studente ingeskerp word. Dic stelling "When teaching system design principles to students, care must be taken not to introduce computer-aided techniques too soon, because it can inhibit the anderstanding of basic principles, and the development of engineering judgement capabitities", is op 19 Januaric 1993 deur dic outeur gemalak tydens dic openbare verdediging van sy Ph.D.-procliskril alan dic Landbouwuniversiteit Wageningen, in Nederland. Hicrdic stelling is nou, sewe jaar later, nog meer van toepassing. 'n Ander stelling wat by bogenocmde geleentheid gemaak is, hel gelui: "In primitive society, communication was mainly by word of moulh; and only the most important information was transferred fiom one generation to the next. In modern society this inherent filler action has, however; been lost, because lec/mological developments allow dissemination of information on a verv large scale. The result is an information explosion (constituting a form of pollation) - which can only be circumvented through increased emphasis on the use of techniques such as artificial imelligence, to filter and control the flow of information." Wat hice bygevoeg kan word, is dat ingenicurs, wat darin geslaag het om dic oorgang vanaf die inligtingsera (blindelingse versameling en stoor vall inligting), na die era van kennis (weldeurdagle versameling. verwerking, interpretasic, en anwending van inligting) te makk. ook uiters noodsaaklik is om inligtingsbesoedcling te help voorkom. Wigdorowitz en Harris ${ }^{2}$ sê dal die opleiding van sulke ingenicurs mocilik gaan wees vir studente en dosente, makar dat dalar nic hicrvan weggedeins kan word nic.

Daar is deesdac 'n tendens om elke Jan Rap en sy maal 'n "IT-ingenicur" te noem. Dit dek 'n hele spektrum vanat rekenaarwetenskaplikes, regdeur persone wat na cnkele weke se opleiding as "Certified System Engineers" kwaliliscer, tol voormalige liksters wat geleer het hoe om rekenarpakkette vir dataversameling te bedryl. Warc ingenicurs word egter onderskei deurdat hulle nic maar net blindelings data manipuleer nic, maar werklik warde loevoeg deur die regte apparaluur en 
programmatuur te gebruik, deur die regte data te versamel, en dit dan krities te evalueer, optimaal te verwerk, en sinvol aan te wend ter verbetering van effektiwiteit. Persone wat maar net blindelings aanhou om data te manipuleer, sal in die inligtingsera agterbly; terwyl dié persone wat grondbeginsels verstaan en kan toepas, die eise wat die era van kennis gaan stel, sal kan hanteer. Dit is die plig van beide die tersiêre opleidingsinstansies en die industrie om seker te maak dat Suid-Afrika gereed is vir hierdie nuwe era. Enersyds moet ingenieurs opgelei word wat kan help om inligtingstelsels sinvol te ontwerp, en om inligting vanuit hierdie inligtingstelsels sinvol te interpreteer en aan te wend; en andersyds rus die verpligting op die industrie om veral die jong ingenieurs die geleentheid te gee om behoorlik in hierdie rigting te ontwikkel, in plaas daarvan om hulle te forseer om blote data-manipuleerders te word.

\section{SAMEVATTING}

Ontleding van vakature-advertensies in 'n enkele uitgawe van die vaktydskrif IEEE Spectrum (hoofsaaklik gerig op elektriese en elektroniese ingenieurs) toon baie duidelik dat daar in die buiteland ' $n$ sterk behoefte bestaan aan ingenieurs met formele opleiding op die gebied van inligtingstegnologie. Verder toon die ontleding ook aan dat 'n groot aantal buitelandse universiteite reeds wegbeweeg het van die tradisionele benaming Departement Elektriese en Elektroniese Ingenieurswese, na name soos Departement Elektriese en Rekenaaringenieurswese of Departement Elektriese en Inligtingsingenieurswese. In Suid-
Afrika bestaan daar tans uiteenlopende standpunte oor hierdie saak. Aan die een kant is daar persone wat glo studente behoort die keuse te hê om 'n kursus in elektriese en elektroniese ingenieurswese te volg, met 'n beduidende komponent inligtingstegnologie daarin opgeneem, terwyl daar aan die ander kant persone is wat voel die nodige kundighede kan later met indiensopleiding verwerf word. Die outeur is van mening dat die buitelandse tendens dat inligtingstegnologie en elektriese en elektroniese ingenieurswese nader aan mekaar beweeg - soos in afdeling 2 hierbo aangedui - wêreldwyd sal toeneem. en dat Suid-Afrika nie anders sal kan as om meer ingenieurs met inligtingstegnologie-vaardighede op te lei nie. Dit behels egter nie bloot kosmetiese veranderinge aan bestaande leerplanne vir elektriese en elektroniese ingenieurswese nie, maar ' $n$ daadwerklike denkwyse-verskuiwing vanaf die inligtingsera (blindelingse versameling en stoor van inligting), na die era van kennis (weldeurdagte versameling, verwerking, interpretasie en aanwending van inligting). Verder verg die pad vorentoe gereelde aanpassings by nuwe behoeftes - en daar kan verwag word dat die snelle ontwikkeling van inligtingstegnologie hierdie aanpassings kort op mekaar sal laat volg.

\section{LITERATUURVERWYSINGS}

1. Anon. (1999). Classified Employment Opportunities, IEEE Spectrum, March, pp. 65-72

2. Wigdorowitz, B., Harris, N. (1998). The Engineer in Transition, Elektron, Nov./Dec., pp. 10-11

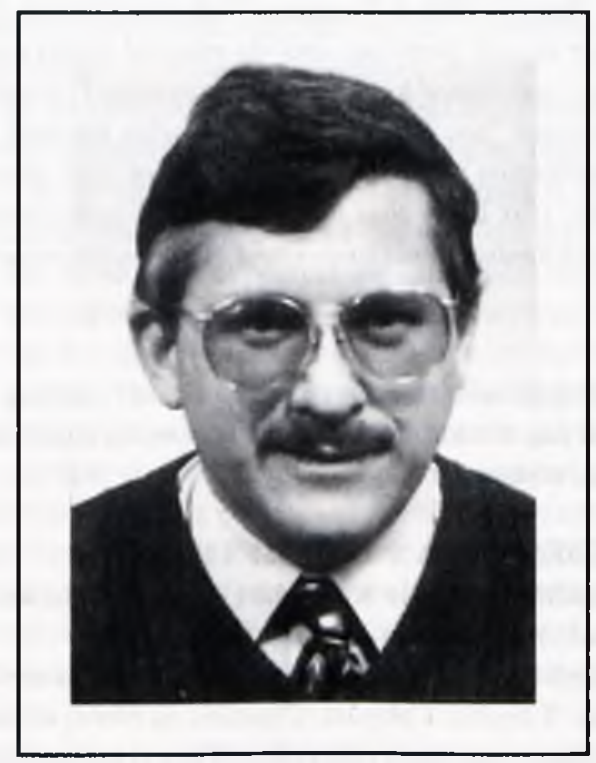

Johan Gouws is op 14 November 1960 in Heidelberg, Gauteng gebore. Hy matrikuleer in 1978 aan die Hoërskool Dr. Malan in Meyerton; en behaal die grade B.Ing. en M.Ing. (Elektries en Elektronies) aan die Randse Afrikaanse Universiteit. Laasgenoemde is met lof behaal, en hy ontvang op grond daarvan die eerste RAU-kanseliersmedalje in 1986. In Januarie 1993 behaal hy 'n Ph.D. in Landbou-ingenieurswese aan die Landbouwuniversiteit Wageningen in Nederland, met 'n proefskrif The Systematic Development of a Machine-Vision Based Milking Robot. In 1998 behaal hy ' $n$ MBA-graad aan die Heriot-Watt Universiteit in Skotland.

Hy was sedert 1983 werksaam by KDI Raadgewende Ingenieurs. die Denel-groep, en Melikon Ingenieurskonsultante. By al hierdie werkgewers het sy verantwoordelikhede onder andere ingesluit: beheerstelselanalise en -ontwerp, stelselingenieurswese, logistieke ingenieurswese, en projekbestuurvir ' $n$ wye verskeidenheid stelsels vir land-, see-, lug-, en ruimtetoepassings. Hy het ook verskillende lynbestuursposisies beklee. In Julie 1993 het hy 'n kontrakaanstelling as Medeprofessor aanvaar in die RAU Departement Elektriese en Elektroniese Ingenieurswese - waar hy in Januarie 1998 tot Professor bevorder is. Hy was betrokke by die vestiging van die RAU TechnoLab - gemik op tegnologiebewusmaking en -geletterdheid; en het ook dic vestiging van die RAU leerplan in elektriese en elektroniese ingenieurswese / inligtingstegnologie geloods. Hy was reeds outeur of mede-outeur van sowat 40 plaaslike en internasionale vakkundige konferensiereferate en publikasies; en van meer as 100 ontwerp-en ander ingenieursverslae vir die Suid-Afrikaanse industrie. Hy is sedert 1987 geregistreer as Professionele Ingenieur. 